\title{
NETL EXTREME DRILLING LABORATORY STUDIES HIGH PRESSURE HIGH TEMPERATURE DRILLING PHENOMENA
}

\author{
K. David Lyons, Simone Honeygan, and Thomas Mroz \\ U.S. Department of Energy, National Energy Technology Laboratory \\ 3610 Collins Ferry Road \\ P.O. Box 880 \\ Morgantown, West Virginia 26507-0880 \\ United States of America
}

\section{ABSTRACT}

The U.S. Department of Energy's National Energy Technology Laboratory (NETL) established an Extreme Drilling Lab to engineer effective and efficient drilling technologies viable at depths greater than 20,000 feet. This paper details the challenges of ultra-deep drilling, documents reports of decreased drilling rates as a result of increasing fluid pressure and temperature, and describes NETL's Research and Development activities.

NETL is invested in laboratory-scale physical simulation. Their physical simulator will have capability of circulating drilling fluids at $30,000 \mathrm{psi}$ and $480^{\circ} \mathrm{F}$ around a single drill cutter. This simulator will not yet be operational by the planned conference dates; therefore, the results will be limited to identification of leading hypotheses of drilling phenomena and NETL's test plans to validate or refute such theories.

Of particular interest to the Extreme Drilling Lab's studies are the combinatorial effects of drilling fluid pressure, drilling fluid properties, rock properties, pore pressure, and drilling parameters, such as cutter rotational speed, weight on bit, and hydraulics associated with drilling fluid introduction to the rock-cutter interface. A detailed discussion of how each variable is controlled in a laboratory setting will be part of the conference paper and presentation.

Key words: Drilling, Deep Drilling, Ultra-deep Drilling, High Pressure High Temperature, HPHT, Model Validation

\section{INTRODUCTION}

For the purposes of this paper and similar studies by the U.S. Geological Survey (USGS) and industry projects [1-5], deep wells are defined as wells drilled for oil and gas having a true vertical depth (TVD) greater than 15,000 feet (4,572 meters). A further distinction of ultra-deep is sometimes made for wells drilled deeper than 25,000 feet (7,620 meters).

The economics associated with drilling deep and ultradeep wells can be staggering. In a cost benchmarking report prepared for the U.S. Department of Energy (DOE), the drilling/tripping cost category was found to average 50 percent of the total cost of deep wells, typically having a total cost ranging from 3 to 8 million U.S. dollars [2]. The report was based on generalized scenarios, making specific assumptions for well drilling in the U.S. Gulf Coast region. For a detailed discussion of these cost benchmarking scenarios, refer to Schlumberger Data and Consulting Services (2005) [2]. Some deep wells cost significantly more than those studied in the benchmarking report.

From an economic perspective, the drilling rate of penetration (ROP) is the single most important factor in determining the cost of drilling a well [2]. Some reports applicable to deep drilling in the U.S. Gulf Coast state that "over $50 \%$ of rig time is spent in the last $10 \%$ of the hole" [3]. Improving the rate of penetration in the deepest segments of deep well drilling through technological advancements is a major focus of this work.

This material is declared a work of the U.S. Government and is not subject to copyright protection in the United States. Approved for public release; distribution is unlimited. 
Effects of Borehole Pressure and Rock Type on ROP

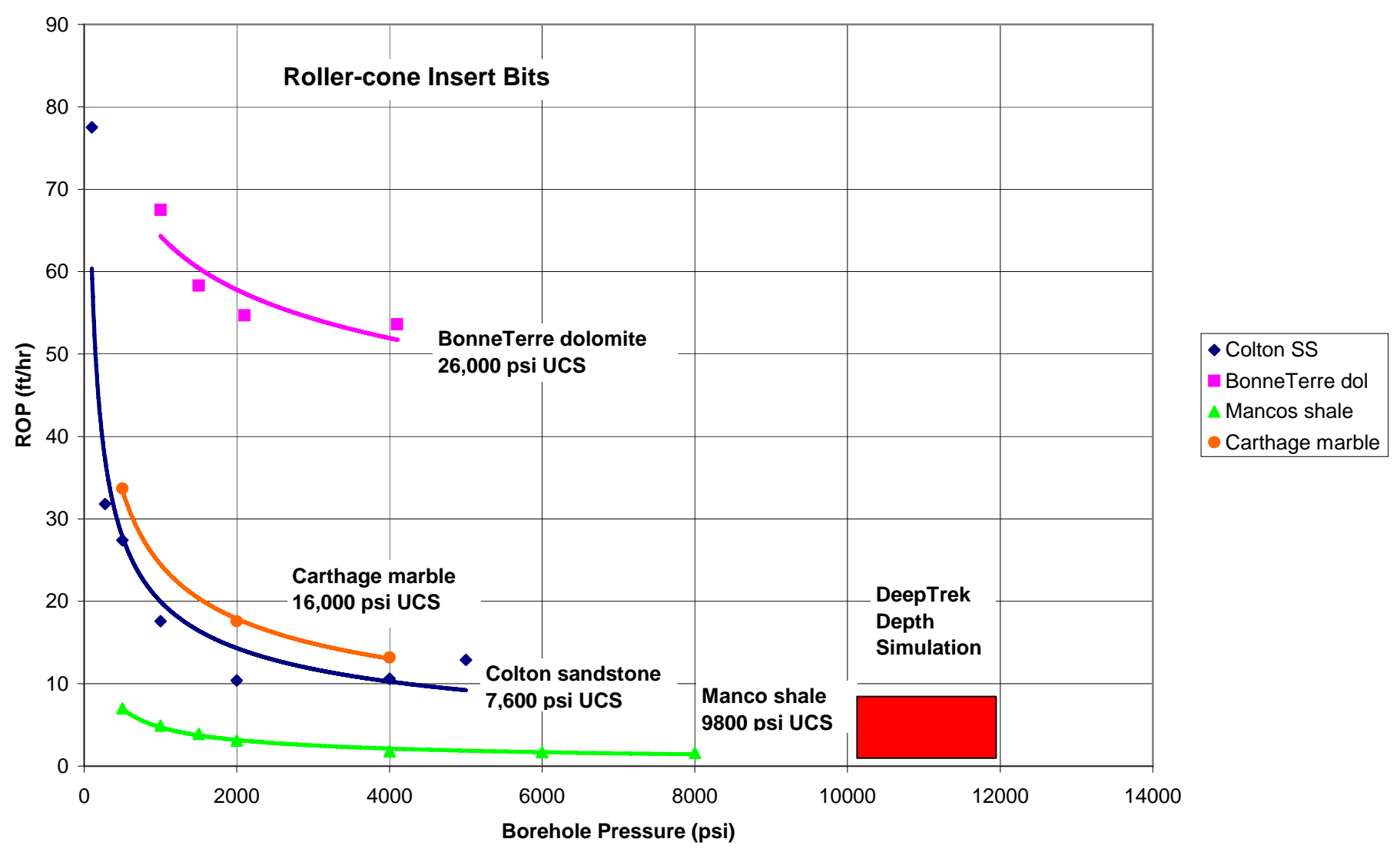

Figure 1. Rate of penetration for various rock types using roller-cone bits [3].

\section{MOTIVATION FOR U.S. GOVERNMENT INTEREST IN DEEP DRILLING RESEARCH}

The potential for natural gas production from deep and ultra-deep resources is considerable. The USGS 1995 National Petroleum Assessment reports that 114 trillion cubic feet (Tcf) of technically-recoverable gas remains undiscovered both onshore and in state waters of the United States alone [4]. Deep gas worldwide estimates from the USGS are also high. The worldwide estimated mean conventional gas resource occurring at depths greater than $4.5 \mathrm{~km}$ is 844 Tcf [4].

Deep gas resources are vast, and deep gas wells are often times large producers. Average production for a deep well having depth greater than 15,000 feet is 6.58 billion cubic feet per well (Bcf/well), whereas the average production from a shallow well having depth less than 5,000 feet is only $0.81 \mathrm{Bcf} /$ well.

In spite of the vast resource and large producing potential, few deep wells are drilled annually. In a recent DOE project, Pinnacle Technologies reported that, in 2002, only about 300 of the estimated 29,000 wells drilled in the United States were deep wells [5]. Drilling activity in 2002 was relatively low and other estimates indicate that typically, 40,000 wells are drilled annually with less than 2 percent being deep wells [6].

Perhaps the leading reason for the disparity between the low number of deep wells drilled and the high production potential of deep gas resources is the enormous costs involved with such ventures. These high costs are a direct result of the technological challenges associated with drilling deep. One key technological challenge, decreasing ROP with increased borehole pressure, is illustrated in Fig. 1 [3].

Without technological advances, the cost of recovering deep resources will remain high. Thus, free market forces dictate that energy costs be sustained at high levels for the private sector to have incentive to develop these costly, deep resources. However, new technology and fundamental understanding of deep drilling processes could reshape the economics of deep resource recovery. Such a reshaping could result in larger gas and oil supply to the market at moderate costs. In this scenario, the public would benefit from relatively stable prices and supply. This last point is the basis for DOE interest in deep drilling research.

This material is declared a work of the U.S. Government and is not subject to copyright protection in the United States. Approved for public release; distribution is unlimited. 


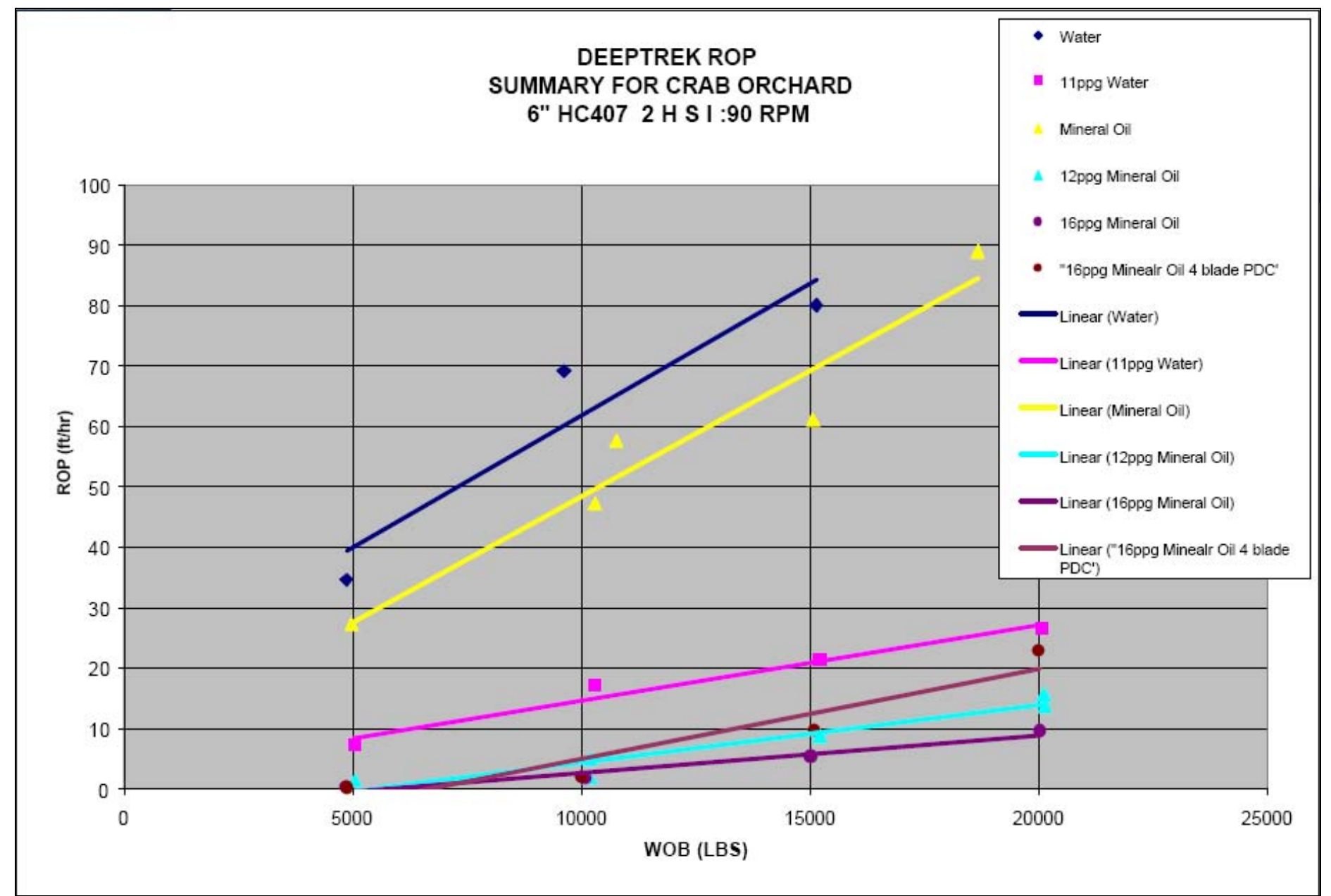

Figure 2. Results from DE-FC26-02NT41657 illustrating the trends of ROP performance in Crab Orchard sandstone as a function of weight on bit for various drilling fluid systems at 10,000 psi confining pressure [3].

\section{PREVIOUS NETLIDOE EFFORTS TO STUDY DEEP DRILLING PHENOMENA}

DOE's current research endeavors in to deep reservoir drilling began with a workshop in 2001 that developed the basis for the Deep Trek program. The Deep Trek program funded selected proposals beginning in 2002 [7]. The program has progressed to assisting with development of High Temperature Electronics and Instrumentation technologies, including down hole instrumentation for measurement while drilling, drilling vibration and monitoring systems, new HPHT cements, electromagnetic telemetry tools, and initial evaluation of current drill bit and mud technology in the HPHT environment [6].

The cost shared DOE project titled "Optimization of Deep Drilling Performance Development and Benchmark Testing of Advanced Diamond Product Bits and HP/HT Fluids to Significantly Improve Rates of Penetration” (DE-FC2602NT41657), which was performed at TerraTek facilities, has accomplished benchmark tests at pressures over 10,000 psi and $150^{\circ} \mathrm{F}$ using a combination of bit designs and drill mud weights and compositions. Tests were performed on sandstone, limestone, and shale rock types that have mechanical characteristics similar to deep reservoirs, such as the Tuscaloosa in the U.S. Gulf Coast and Arbuckle in the southwestern U.S. [3].

Selected ROP benchmarking results for DOE's project with TerraTek are presented in Figs. 2 and 3 [3]. In these figures, the effect of the drilling fluid on ROP performance is overwhelming. Also, for each rock type and fluid system used, the pure base fluid (e.g., water, mineral oil, or DF2 diesel fuel) yields a much higher ROP than does its corresponding drilling mud, which is weighted and laden with dissolved solids. This trend is noted for other rock types and bits, and thus is not simply an anomaly [3]. Among all the variables studied by Black, et al. [3], the influence of drilling fluid type had the largest effect on ROP.

Benchmarking results also indicate some dependence of specific drill bits on drilling performance; however, the best performing bits varied with the rock type being studied. For instance, it was reported that a 7-blade polycrystalline

This material is declared a work of the U.S. Government and is not subject to copyright protection in the United States. Approved for public release; distribution is unlimited. 


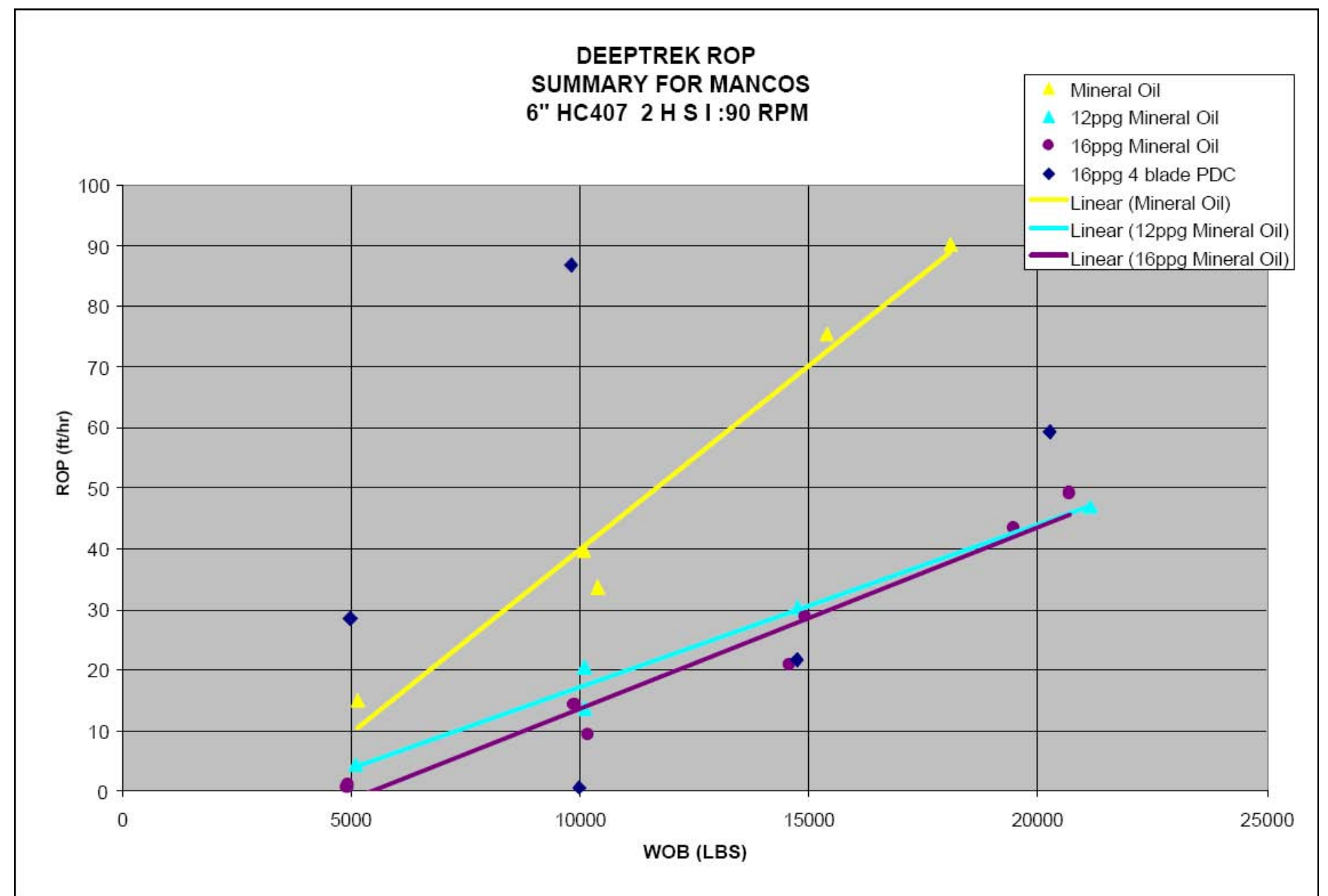

Figure 3. Results from DE-FC26-02NT41657 illustrating the trends of ROP performance in Mancos shale as a function of weight on bit for various drilling fluid systems at 10,000 psi confining pressure [3].

diamond cutters (PDC) bit had higher ROP than did a 4-blade PDC bit in Crab Orchard Sandstone and Carthage Marble but not in Mancos Shale, where the 4-blade PDC had superior performance [3].

The quest to further study and understand the fundamental behavior of deep drilling systems is a compelling one for DOE. The results from the benchmarking project described above form an important basis for the development of an Extreme Drilling Laboratory to study of HPHT drilling phenomena.

\section{DESCRIPTION OF NETL'S UDS PHYSICAL SIMULATOR}

To study ultra-deep drilling phenomena in an extensive, onsite effort, the National Energy Technology Laboratory (NETL) has participated with TerraTek, a Schlumberger company, in a Cooperative Agreement titled "Ultra Deep Drilling Cost Reduction” (Project DE-FC26-05NT42654). As part of this agreement, an ultra-deep single cutter research drilling simulator (referred to as the UDS) is being designed and constructed to study fundamental behavior and interactions among drilling fluids, bit cutters, and rock under HPHT conditions.

The UDS will be used to simulate bottom-hole conditions of wells drilled in excess of 15,000 feet (4,572 meters) TVD. At such locations, drilling fluids and reservoir fluids may be at high temperature and extreme pressure. Therefore, the UDS is designed to test bit cutters contacting rock core in a heated pressure vessel operating with an internal fluid pressure up to 30,000 psi (2068 bar) and temperature up to $481^{\circ} \mathrm{F}\left(250^{\circ} \mathrm{C}\right)$. A computer-generated rendering of the UDS is shown in Figure 4. The UDS also has the capability to circulate the same drilling fluids within its system that would be used in practice-every effort is made to provide realistic drilling mud hydraulics.

During a typical test, the UDS rotates a rock core beneath a stationary cutter. The cutter's geometry, orientation, and radial placement are all degrees of freedom for any particular experiment. Like the bit cutter, the selection and placement of drilling fluid injection nozzle(s) near the cutter will be a

This material is declared a work of the U.S. Government and is not subject to copyright protection in the United States. Approved for public release; distribution is unlimited. 


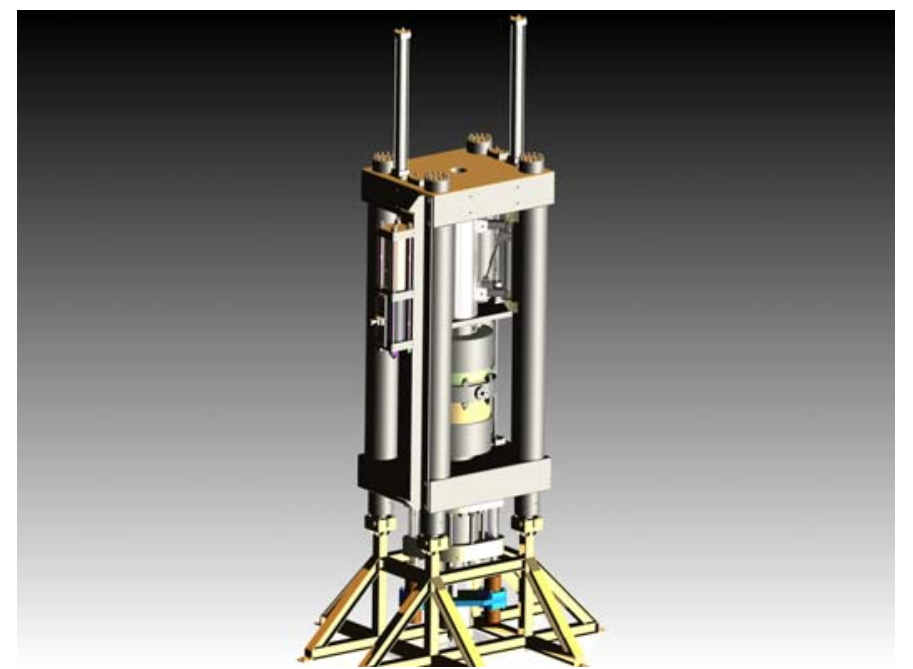

Figure 4. Computer-generated rendering of the UDS to be used at NETL to study deep drilling phenomena.

degree of freedom for any given test. In fact, placement of the nozzle, fluid volume flow rate, and fluid jet velocity are the primary mechanisms for obtaining the mud hydraulics of interest for a particular experiment.

The angular speed of the rock core can be controlled up to 60 RPM, and the linear displacement rate of the core can be controlled up to 2.7 inches per second $(6.8 \mathrm{~cm} / \mathrm{s})$ such that the maximum total linear displacement per test is approximately 2 inches $(2.5 \mathrm{~cm})$. The stationary cutter will be outfitted with a three-axis load cell and interfaced with a high-speed data acquisition system to record test variables of interest.

Some test configurations will also provide limited ability to control pore pressure in the rock and simulate the effects of spurt loss. This is done by including a separate reservoir of fluid with pressure control, contacting the bottom face of the studied rock core (i.e., opposite face of the cutter-contacted side). The permeability of the rock, which is usually known, and the pressure difference between the drilling fluid and the simulated reservoir fluid will establish a pore pressure gradient along the axis of the studied rock. In some instances, fluid ingress/egress from the rock face may be observed, primarily via X-ray techniques described below.

Anticipating that the UDS will be called upon to perform numerical model validation, the UDS will be equipped with a linear X-ray system to capture images of the rock-cutter interface during a cutting event. X-ray imaging is selected so that the UDS may test with drilling fluids used in field applications, many of which are optically opaque, thus limiting optical observation of cutting phenomena at HPHT conditions. By using X-ray observation techniques, it will be possible to physically observe the solid-phase strain and flow of rock over extremely small time increments.

\section{FUTURE PLANS TO EMPLOY NETL ASSETS TO DEEP DRILLING RESEARCH}

When the UDS system becomes fully operational, laboratory investigations will create HPHT conditions in a system containing rock, drill cutter, and actively flowing drilling fluids. In this system, observations of rock strain under the bit followed by generation and flow of rock cuttings will be taken. Such physical observations will be critical in determining the fundamental mechanisms of rock failure and chip formation under a drill bit in HPHT environments.

In a related project, NETL is also exploring the use of nanofluids for use in HPHT drilling fluids. In addition to seeking field application possibilities for these nanofluids, they may also be used in some studies involving the UDS. In such studies, nanofluids, which are nanometer-sized solid particles suspended in liquids, may be substituted for the drilling fluid. The objective of these tests would be to observe the possible ingress of drilling fluid into the rock during a cutting event. The use of nanofluids are thought to be advantageous in this task because the particles can be easily identified by the X-ray system, and the nanofluid can be prepared in such a way that the particles do not exhibit ionic characteristics.

Ultimately, the enhanced understanding of deep drilling phenomena will enable better and more predictive models. Such an understanding of the mechanics of cutting high compressive strength reservoir rocks at extreme depths will enable technological advancements that may exhibit superior drilling performance at higher temperatures and pressures.

\section{ACKNOWLEDGMENTS}

The authors wish to acknowledge Dr. Sidney Green, Dr. Arnis Judzis, and Mr. Robert Griffin, all of TerraTek, a Schlumberger Company. These individuals have been of great assistance to DOE through their contributions under Cooperative Agreement DE-FC26-05NT42654. Additionally, the authors wish to acknowledge Mr. Allan Black and Mr. Homer Roberson, also of TerraTek, and Dr. Tim Grant of NETL, for their work under Cooperative Agreement DE-FC26-02NT41657, which formed much of the foundation for the research directions described in this paper.

\section{REFERENCES}

1. Lyons, K. D., 2006, "Extreme Drilling Laboratory to Advance Understanding of Bit-Rock-Fluid Interaction," GasTIPS, 12(2), pp. 17-18, http://www.netl.doe.gov/ technologies/oil-gas/ReferenceShelf/GasTIPS/ GasTIPS.html

2. Schlumberger Data and Consulting Services, 2005, "Benchmarking Deep Drilling," Final Report, U.S. Department of Energy, http://www.netl.doe.gov/ technologies/oil-gas/ReferenceShelf/RefShelf_archive. html\#Reports05

This material is declared a work of the U.S. Government and is not subject to copyright protection in the United States. Approved for public release; distribution is unlimited. 
3. Black, A. and Judzis, A., 2006, “Optimization of Deep Drilling Performance - Development and Benchmark Testing of Advanced Diamond Product Drill Bits \& HP/HT Fluids to Significantly Improve Rates of Penetration," Topical Report, U.S. Department of Energy, http://www.osti.gov/bridge/index.jsp

4. Dyman, T. S., 2002, "Natural Gas Resources In Deep Sedimentary Basins,” Final Report, U.S. Department of Energy, http://www.osti.gov/bridge/index.jsp

5. Pinnacle Technologies, Inc., 2006, "Stimulation Technologies for Deep Well Completions," Final Report, U.S. Department of Energy, http://www.osti.gov/ bridge/index.jsp

6. National Energy Technology Laboratory, 2006, “DOE's Deep Trek Program-Bringing New Gas To Market," Fact Sheet, www.netl.doe.gov

7. National Energy Technology Laboratory, 2002, "New DOE Projects to Develop High-Tech Drilling Systems to Tap Deep Natural Gas,” Techline, www.netl.doe.gov

This material is declared a work of the U.S. Government and is not subject to copyright protection in the United States. Approved for public release; distribution is unlimited. 